\title{
STRONG OR WEAK TIES? BRITISH AND INDIAN EXPATRIATE SCIENTISTS FINDING JOBS IN BOSTON
}

\author{
William S. Harvey
}

\begin{abstract}
This paper analyses the different social networks that British and Indian scientists use to obtain job information in the pharmaceutical and biotechnology sector around Boston, Massachusetts. I argue that individual social networks are critical in helping highly skilled migrants find jobs. British and Indian scientists used both strong and weak ties to obtain jobs and there was no significant difference between senior and junior workers in terms of whether they relied on strong or weak ties. I argue that the terms strong ties and weak ties are problematic because they are not clearly understood or mutually exclusive.
\end{abstract}

\section{Key words}

Social networks; Strong and weak ties; British expatriates; Indian expatriates; Boston; Pharmaceutical and biotechnology sector; Job information

\section{INTRODUCTION}

The experiences of getting a job have become increasingly important within the social sciences literature. Although there is a fairly extensive literature on how gender, race and class affect individuals obtaining jobs (Pratt and Hanson 1994; Hanson 2000; Chapple 2002; McDowell 2005; Squires and Kubrin 2005; Gray et al. 2007; McDowell 2007), there has been less analysis of migrants (Bagchi 2001; Bashi 2007; Ooka and Wellman 2003; Poros 2001). Furthermore, there is an extensive literature on expatriates (Beaverstock 2002, 2004, 2005; Saxenian 2002, 2006; Baláž and Williams 2004; Williams and Baláž 2005; Walsh 2006; Williams 2006; Scott 2006, 2007; Larner 2007; Chacko 2007), but little has been written about how highly skilled migrants find jobs. This is important because some migrant groups may prove to have a strategic advantage or disadvantage over other groups and the local indigenous population.

This paper analyses the different individual social networks that British and Indian scientists use to obtain job information. In particular, there is a critique of how important family members and friends, colleagues and business 
associates, and other expatriates are in providing British- and Indian-born scientists with new job information. This paper argues that individual social networks are significant for highly skilled British and Indian scientists looking for employment. However, it is argued that the use of the terms 'strong tie' and 'weak tie' are not appropriate in the context of this research. Senior and junior workers within both groups used many types of social contacts for obtaining job information and the boundary between strong and weak ties is so blurred that it is questionable how useful these terms are in classifying the different social networks that highly skilled migrants use for finding jobs.

\section{THEORY}

This section analyses the literature on social contacts and getting jobs as well as the debate over the importance of strong and weak ties.

\section{Social contacts}

Social contacts are vital in helping people to secure jobs because they provide jobseekers with important additional information about jobs that are not available through formal applications (Granovetter 1974, 1995; Heimer 1984). Granovetter (1995: 14-15) argues: "The more satisfied individuals are in their jobs, the more likely they are to have found them through contacts." From the perspective of a person looking for a job, he or she relies on the strategic advantage of a social contact who will know more about what skills the employer is looking for as well as more detailed characteristics of the job. The recommender meanwhile relies on the person who is looking for a job to be a good employee to maintain his or her reputation with colleagues. In both cases, there is a level of trust and a tacit understanding of what the other person expects. Poros (2001) argues that social networks are critical in helping Asian Indian migrants secure high technology jobs in London and New York. In particular, before a migrant has arrived in a new country, or upon recent arrival, social networks can help them connect and become embedded within local labour markets (Poros 2001).

Scholars recognise that highly skilled migrants rely on social networks to obtain new job opportunities (Bagchi 2001; Alarcón 1999; Poros 2001; Raunio and Sotarauta 2005). Raunio and Sotarauta (2005: 8), for example, argue that social networks are a crucial mechanism for securing jobs for highly skilled migrants in Finland:

"Two main methods of seeking a new job were: contacting friends or people met through work (professional contacts) and searching the Internet. This intensive use 
of various social and virtual networks is rather characteristic of migrants and is certainly a result of global corporations' world wide operations and professional contacts from which such opportunities can be derived."

They rightly contend that internationally mobile experts see their field as a network of nodes of their own particular expertise, rather than situated in certain nation states and cities. Lin (2001) agrees in his argument of social capital, which suggests that workers are motivated by the need to engage other actors in order to access their resources for the purpose of gaining better outcomes. In this case, highly skilled workers use their social networks to find out about job information which they otherwise would not be aware of:

"In the usual imperfect market situations, social ties located in certain strategic locations and/or hierarchical positions (and thus better informed on market needs and demands) can provide an individual with useful information about opportunities and choices otherwise not available" (Lin 2001: 19-20).

Social networks are not only important in enabling people to hear about new job vacancies, but also in influencing recruiters who play a key role in the decision of hiring people (Lin 2001). However the analysis should develop beyond the statement that people regularly obtain jobs through social networks. What is less understood is in what contexts people use social networks for job purposes. Furthermore, are there regional, sectoral, or group differences in the extent to which highly skilled migrants use social networks to obtain new job information?

Some scholars argue that migrant groups differ in the extent to which they use social networks for obtaining jobs. Alarcón (1999), for example, shows that Mexican and Indian scientists and engineers in Silicon Valley used contacts from their previous universities for helping them obtain their first job. However, he finds that Indian migrants use social networks more than Mexican migrants for job information for three main reasons. First, U.S. immigration policy has favoured skills and education which has helped maintain a highly educated network from India. Second, policies in India have targeted the software industry which has helped professional networks to develop between India and the U.S. Third, English is the official language of higher education in India which gives Indian engineers and scientists a competitive advantage in forming social relationships with professionals in the U.S. Dustmann (1994) also argues that strong verbal and written language skills are important in helping migrants obtain employment and better incomes. It is not clear from the literature whether other migrant groups who speak English as their first language experience similar success at forging social networks with local professionals and therefore hold a competitive advantage in the labour market. Williams (2007: 38) 
argues that it is not necessarily differences in language ability, but "[...] those educated in the host, as opposed to the origin, country will have comparative advantages in the recognition of country-specific knowledge." In short, to what extent do migrant groups differ in their use of social networks for obtaining new job information?

Granovetter (1974, 1995) was one of the first to make the connection between the flow of information within social networks and finding a job. He found that professional, technical and managerial (PTM) workers in Newton, Massachusetts rely on their personal contacts to gain information about new jobs, rather than more formal and impersonal routes. ${ }^{1}$ He argues that PTM workers use three principal methods to find out about jobs. First, formal means such as advertisements, employment agencies and internship programmes. Second, personal contacts when people know individuals in another capacity other than searching for jobs. Third, direct application when an individual applies for a job directly with a company and has not heard about a specific job opening. Granovetter (1995: 11) found that personal contacts (55.7\%) were cited as significantly more important as a job source than formal means $(18.8 \%)$ and direct application $(18.8 \%)$.

"The PTM workers to whom I spoke believed that information secured through personal contacts is of higher quality than that available by other means; a friend gives more than a simple job-description - he may also indicate if prospective workmates are congenial, if the boss is neurotic, and if the company is moving forward or is stagnant" (Granovetter 1995: 13).

Although his work shows how a small PTM group use their social relationships to find jobs, there is little reference to whether social networks may differ depending on whether the group is indigenous or foreign-born. In addition, Granovetter (1995) does not discuss in any detail whether social networks may vary from one sector to another, or whether the density of social networks may vary within a firm. These issues are important because there may be specific trends in the use of personal contacts for job purposes.

A key problem in economic and social theory, according to Granovetter (1995), is the extent to which individuals behave 'rationally'. He finds that although some individuals actively seek out personal contacts, others are constrained to a number of alternatives from which they choose. Chance meetings, poorly remembered acquaintances, and information passed on from strangers are just a few examples of how job information is exchanged in a

${ }^{1}$ Personal contacts are people that individuals know either closely or have at the least met in person through their work or social life. 
serendipitous manner. In addition, although scholars have argued that individual agency is important for seeking jobs, actors are also limited by the size and structure of a social network. Bagchi (2001a: 142-143) argues that macrolevel factors can affect the extent to which migrants participate in different types of social networks:

“[...] I emphasised macro-level changes in network availability due to legislative measures put in place in the receiving country. However, these macro-level effects have an important impact on individual network usage among professionals and suggest a shift in emphasis away from strong tie networks towards weak tie networks in the face of legislative decisions, or vice versa."

This explains why groups in different regional economies vary in the types of social ties they use for obtaining job information. Although Granovetter (1974) is right that job information is often restricted for certain people, their social networks are purposeful because important information is still exchanged and potential key contacts are forged.

\section{Strong ties versus weak ties}

Granovetter (1973) makes an important distinction between strong and weak ties. He argues "[...] the strength of a tie is a (probably linear) combination of the amount of time, the emotional intensity, the intimacy (mutual confiding), and the reciprocal services which characterize the tie" (Granovetter, 1973: 1361). Simplistically, strong ties are close colleagues, friends and family members, whereas weak ties are business associates from other companies, acquaintances or people that are less well known to the individual. Marsden and Campbell (1984: 482-483) argue: "Little sustained attention has been given to the measurement of the concept of tie strength, and the (presumably differential) accuracy of the different measures that have been used to index it." However, they conclude that Granovetter's (1974) measurement of 'closeness' is the best indicator of tie strength because this "[...] measure is free of contamination by other indicators and predictors in all three samples" (Marsden and Campbell, 1984: 498). One of the problems with using closeness as a measurement of tie strength is the underlying assumption that the title of the social relationship should determine the strength of the tie. Family members, for example, could be weak ties and colleagues could be either strong or weak ties. It is questionable how appropriate it always is to use the terms strong tie and weak tie to help us to understand what types of social contacts people use to obtain jobs.

Granovetter (1973) shows that weak ties are more important than strong ties for obtaining high-end jobs because weak ties expose people to different social circles and therefore new information, including diverse information about 
jobs. . Lin et al. (1981) also argue that social relations with weak ties are critical in helping people secure information that they do not already know. Burt (2004: 349-350) argues in his 'structural holes' hypothesis that individuals who position themselves near holes in a social structure are more likely to have access to better ideas because:

“[...] opinion and behavior are more homogeneous within than between groups, so people connected across groups are more familiar with alternative ways of thinking and behaving, which gives them more options to select from and synthesize. New ideas emerge from selection and synthesis across the structural holes between groups."

Weak ties are arguably more significant than strong ties because: "The closer individuals are to a bridge in a network, the better social capital they will access for instrumental action" 2 (Lin 2001: 69-70). Poros (2001: 245) distinguishes between 'interpersonal ties', which are social relationships with family members and friends, and 'organizational ties', which refer to the mediating structures of a firm and include social relationships with colleagues and supervisors. She finds that organizational ties, which are typically weak in Granovetter's (1973) sense, "[...] generally provide a wider and better range of opportunities than interpersonal ties, given that the requirements of the organization can be satisfied" (Poros 2001: 255). She argues that four broad types of migration streams (solitaries, chains, recruits, and trusties) can help explain why migrant professionals vary in their participation in social networks. This in turn channels these migrants into different occupations within their host countries.

Some scholars argue that migrants with greater educational backgrounds are more likely to rely on weak ties than migrants with less education (Ooka and Wellman, 2003: 12). This suggests that highly skilled migrants would be less likely to rely exclusively on family and friendship ties because they have more diverse social contacts. However, Ooka and Wellman (2003: 14; original emphasis) also argue "[...] intra-ethnic ties, and not inter-ethnic ties, benefit job seekers in high-status ethnic groups." In particular, they show that German and English Canadians use their intra-ethnic contacts to secure higher income jobs. In contrast, low-status ethnic groups such as Ukrainians principally use interethnic ties for job referrals. In other words, highly skilled migrants use their own expatriate social networks for job information, whereas low skilled migrants use the social networks of other migrant groups. What remains unclear from the highly skilled migration literature is the extent to which migrants use different

\footnotetext{
2 A bridge allows people in one social network to have access to the resources embedded in nodes in another cluster which otherwise would not be available (Lin 2001).
} 
types of social ties to obtain jobs.

Some scholars have argued that strong ties are often more important than weak ties particularly when information about job opportunities is highly valued and not readily available (Bian and Ang 1997). Mattingly (1999) shows that paid household workers in San Diego, California, tend to use three principal forms of close social contacts to find work: first, through subcontracting arrangements; second, through job referrals from other domestic workers and third, through male family members. She argues that:

"All three are examples of what Granovetter (1973) called "strong ties," and just as he pointed out, they are contacts that are easy for some immigrant women to access, particularly if they live in ethnic enclaves. They do not, however, always lead to the most valuable employment information" (Mattingly 1999: 65-66).

Bian and Ang (1997) find that guanxi3 networks in China and Singapore are important in enabling workers to both obtain and change jobs. They argue that unlike Western examples, which demonstrate the importance of weak ties, their research emphasises the strength of strong ties:

"We have looked to guanxi networks, common to Tianjin and Singapore, to account for the fact that jobs are channelled through strong ties more frequently than through weak ties. We have described the tensions between employees and employers in the different labor market contexts in Tianjin and Singapore. The tension in Tianjin was for a potential job changer to fight against a bureaucratic system resisting job mobility. The tension in Singapore is for employers to be sure about the reliability of workers with company loyalty. In both cases, guanxi networks of job changers provide channels to release these tensions" (Bian and Ang 1997: 1001).

Wegener (1991: 69) suggests that there is social strata with strong and weak ties, with people holding low-end jobs preferring to use strong ties, whereas people that hold high-end jobs prefer to use weak ties to advance their careers. In other words, high-end workers need to reach out beyond their network for information about more prestigious jobs, whereas job seekers with lower positions can contact people of a higher prestige within their own network for information about better jobs. This distinction between strong ties for low-end jobseekers and weak ties for high-end jobseekers is arguably reductionist because in practice people will reach out to both types of social contacts.

Sanders et al. (2002) argue that family and friends are important in helping migrants secure jobs, although they focus on immigrant minorities of both sexes

${ }^{3}$ Guanxi literally means relationship or relation, but is extended to mean the connections that allow favours to be exchanged between people (Bian and Ang 1997). 
who have significantly less human capital than Granovetter's (1973) white male sample. They argue: "[...] critical exchanges of information often flow through chains of actors, chains that can be weak, strong, or ambiguous. In many cases, the chain character of these information exchanges makes it difficult to attribute the bridge tie to a particular individual" (Sanders et al. 2002: 307). Bashi (2007) argues that rather than thinking about job opportunities passed on through dyadic chains, it is more appropriate to talk about a few influential individuals who specialise in different forms of social capital, known as 'hubs', who hoard jobs for their migrants:

"Once the newcomer performs well, the solidity of the hub's reputation increases,
and it becomes more so with the satisfactory performance of each new hire. The
repetition of this cycle of network hoarding and hiring is what creates a hub's
workplace reputation for making recommendations" (Bashi 2007: 262).

Bashi (2007) argues that these hubs do not hold strong ties with migrants, but rely on their expertise to assess whether particular weak ties are the right people to fill overseas job openings. These findings are critical because they show that migrants will move abroad into new jobs even when they have had little contact with a hub prior to their migration. Bagchi (2001b) argues that the social networks of immigrant professionals vary by occupation. Physicians and nurses, for example, rely more on spousal sponsorship than scientists and engineers. In addition, "Given their superior resources, wealthier and more educated immigrants possess the ability to obtain information regarding visas, to conduct extensive job searches and to visit the destination area before actually emigrating; all of which ease entry" (Bagchi 2001b: 10).

Massey et al. (1994) also argue that strong ties are more important than weak ties for helping migrants integrate into a new society. They show that having friends and relatives (strong ties) with migratory experience improves the efficiency and effectiveness of finding jobs and securing higher wages among male Mexican migrants. Wong and Salaff (1998) argue that middle class emigrants from Hong Kong relied more on professionals in their field as well as friends (strong ties), whereas working class emigrants, relied on family members (strong ties) in arranging their resettlement abroad during the period of the British hand-over of Hong Kong to China. These differences existed because the middle-class and working-class groups varied in the social networks they used for helping them secure opportunities outside of Hong Kong. Theoretically, the above examples are important because they suggest that although migrants use different personal connections, they tend to preference strong ties over weak ties. Although family and friends are an important source of new job information, arguably workers in highly skilled and specialised employment sectors are 
unlikely to rely on social contacts from family and friends because they are less likely to be working in the same field and therefore do not hold key job information. I argue that it is problematic to assume that people use either strong or weak ties.

It is unclear whether other types of social ties such as expatriate social networks help individuals obtain jobs. Ooka and Wellman (2003: 4) argue "Few studies have focused on comparing the benefits of using ties within one's own group with the benefits of using ties with members of other ethnic groups". They are right to argue "[...] we cannot automatically assume that using intraethnic ties in job searches is always beneficial or disadvantageous. The advantage of using particular social contacts depends on what kinds of resources are controlled within and outside of one's own ethnic group in the particular labor market" (Ooka and Wellman 2003: 6). As discussed above, their research in Toronto suggests that intra-ethnic social networks are more important than interethnic social networks for helping job seekers in 'high-status ethnic groups.' "For example, $85 \%$ of the English who use personal contacts use intra-ethnic ties. English men who use intra-ethnic ties have much higher incomes (mean=\$20,510) than those who use inter-ethnic ties $(\$ 14,125) "$ (Ooka and Wellman 2003: 14). It is important to conduct further research to establish whether people that use intra-ethnic social ties hold more senior positions.

Timing is important since someone might recommend a job to an acquaintance when there are plenty of jobs available for their friends, but they might not recommend a job to an acquaintance when jobs are scarce (Kadushin 2004a). It is clear that strong and weak ties are significant in different contexts: "[...] for the ability of actors to secure benefits by virtue of membership in social networks or other social structures" (Portes 1998: 6). However, greater explanation is needed into why actors depend upon various types of relationships in different contexts. Crucially, we need to extend the analysis beyond the dualism of strong ties versus weak ties to show that individuals use both types of social networks differently according to the type of social relationship and information they are seeking (Grabher 2006). "Given these examples, purely strong and weak ties represent two ends of a continuum with some interactions falling more clearly towards one end than the other depending on the characteristics of the relationship" (Bagchi 2001a: 37). Social relationships can also become stronger or weaker over time which questions whether we need to use the terms strong tie and weak tie.

Although there are occasions when people preference strong ties in lieu of weak ties, or vice-versa, in practice it makes little sense, other than for conceptual 
purposes, to separate the two. A number of scholars argue that the debate should move beyond the dichotomy of strong ties versus weak ties (Elliot, 2001; Ooka and Wellman 2003; Montgomery 2008). Instead, there should be greater attention to the complexity of social networks. Ooka and Wellman's (2003) analysis of different ethnic groups in Toronto demonstrates that migrants use both strong and weak ties for the purposes of obtaining new job information. They suggest that an individual will use strong or weak ties depending upon his or her composition of friendship networks. "More than $80 \%$ of those job seekers whose friendship networks were ethnically homogenous used ties within their own ethnic group. By contrast, almost $60 \%$ of those job seekers whose networks were ethnically heterogeneous used ties outside of their own ethnic group" (Ooka and Wellman 2003: 16). Montgomery (2008: 77) finds that software engineers from India and Taiwan used strong and weak alumni ties for the

purposes of gaining job and business information. "As old classmates scatter around the world, the alumni list may combine the benefits of strong and weak ties deep commitments and unique information."

In short, there is a need to look at the different types of social contacts that migrants use to obtain new job information, including family members, friends, colleagues, expatriates, acquaintances and other professionals. To what extent can it be argued that workers use a combination of strong and weak ties and use different types of contacts depending upon their position within the company and the timing of their job search? This is important because the social networks of different migrant groups can demonstrate whether they have an advantage or disadvantage over other groups when seeking new jobs.

\section{METHODOLOGY}

I chose Boston as the location for my research because it holds a large concentration of global pharmaceutical and biotechnology companies and therefore it was an appropriate region for analysing scientists. Boston also hosts several world-renowned universities such as Harvard University and the Massachusetts Institute of Technology (MIT). I decided to interview British- and Indian-born scientists to explore the differences in individual social networks between highly skilled migrant groups.

I selected both migrant groups because they had a similar representation of expatriates in the Boston area, according to the U.S. Census Bureau (2000). In 2000, 2,422 British-born people and 2,618 Indian-born people were living in 
Boston (0.9 percent of the total population of the city). ${ }^{4}$ Of all the engineering and technology companies in Massachusetts founded by migrants, 10 percent were founded by British and 10 percent were founded by Indian migrants (Wadhwa et al. 2007: 17). Indian migrants are also the second highest group after China and British migrants are the fourth highest group after Canada in terms of Intellectual Property contributions in the U.S. between 1998 and 2006 (Wadhwa et al. 2007: 25). In short, British and Indian scientists have made an important contribution to the high technology sector in the U.S.

I conducted structured interviews with two hundred and two British and Indian scientists between January and June of 2006, including one hundred and one British and one hundred and one Indian scientists. The average age of British respondents was 42 and the average age of Indian respondents was 39. Table 1 shows that the age distribution of British and Indian scientists was similar, but more Indian scientists were in the 26-35 age range and more British scientists were in the 46-55 age range. 18 percent of my British sample and 28 percent of my Indian sample were women. Having said this, there were no apparent differences between men and women in terms of their experiences of obtaining job information.

All British and Indian scientists held strong educational qualifications. Table 1 shows that most British and Indian scientists held a Ph.D or an M.D. with the remaining respondents holding at least a master's or bachelor's qualification. Indian scientists held more advanced educational qualifications than British scientists. Although the age distribution shows that the average British respondent is older than the average Indian respondent, the job titles of both groups shows a marked difference. Table 1 shows that British respondents hold significantly more senior management positions, particularly in the VicePresident category, compared to Indian scientists who hold significantly more Senior Scientist and Scientist positions. When taking consideration of age, British respondents still hold more senior positions than Indian scientists even though the latter hold more advanced educational qualifications. This is important because scholars argue that workers who are older and hold senior positions within companies will have more information about jobs than workers who are younger and hold junior positions (Heimer, 1984).

\footnotetext{
${ }^{4}$ This figure does not include the far greater number of scientists that commute from other parts of the Boston metropolitan area. British and Indian scientists lived in a variety of places from central locations such as Boston or Cambridge to suburbs such as Lexington and Wellesley.
} 
Table 1: The age, educational qualifications and company positions of British scientists in Boston

\begin{tabular}{lllll}
\hline $\begin{array}{l}\text { Age } \\
(\%)\end{array}$ & $26-35$ & $36-45$ & $46-55$ & $56+$ \\
British & 24 & 47 & 25 & 4 \\
Indian & 33 & 51 & 14 & 2 \\
\hline $\begin{array}{l}\text { Highest educational } \\
\text { qualification }\end{array}$ & Bachelor's & Master's & $\begin{array}{l}\text { Doctorate or } \\
\text { equivalent }\end{array}$ & \\
$(\%)$ & & & 72 & \\
British & 15 & 13 & 77 & \\
Indian & 7 & 16 & Manager or & Researcher or \\
Company position & CEO or & Vice-President & senior scientist & scientist \\
$(\%)$ & President & or Director & 19 & 21 \\
British & 10 & 50 & 35 & 36 \\
Indian & 7 & 22 & & \\
\hline
\end{tabular}

Structured interviews were conducted with scientists from large, medium and small firms as Graph 1 illustrates. ${ }^{5}$ With my British respondents, 58 percent worked for large, 21 percent for medium and 21 percent for small companies. With my Indian respondents, 64 percent worked for large, 25 percent for medium and 11 percent for small companies. The majority of respondents worked for companies incorporated in the U.S. Approximately two-thirds of the interviews were conducted over the telephone and the other one-third were conducted face-to-face. Although face-to-face interviews typically lasted longer than telephone interviews, there was no significant difference in terms of the quality of data that respondents provided. The telephone interview was used more than the face-to-face interview because respondents preferred this type of interview given their busy work schedules.

Since there was no formal register of British and Indian scientists working in pharmaceutical and biotechnology companies around Boston, gaining access to interviewees was initially through a small number of key gatekeepers. Contacts were also made through attending professional events such as conferences, workshops and networking meetings, as well as social events such as sports and social clubs. These different access avenues meant that I

${ }^{5}$ I use the following categories to distinguish between different sized firms. Small firm: 0-49 employees; medium firm: 50-249 employees; large firm: 250 or more employees. 
interviewed people from a range of groups within the British and Indian expatriate communities rather than from a small number of specific groups. Further respondents were successfully contacted through the snowballing technique.

\section{ANALYSIS}

This section assesses the importance of family members, friends, colleagues, business associates and expatriates as sources of new job information. It is recognised that some of these social categories could be regarded as both strong and weak ties. Heimer (1992: 147) rightly argues: "Precise job descriptions often are too narrow, either because they do not include the full range of tasks associated with a given occupation or because they fail to take into account the full range of variation in customers and clients." This paper also emphasises the importance of moving beyond the dichotomy of strong versus weak ties. Although they are not always mutually exclusive, different social categories are either coded as strong or weak ties depending on the nature of the social relationship between British and Indian respondents and different actors. Poros (2001: 245) argues that distinguishing social ties based on how people meet can help remove some of the ambiguities associated with labelling them. Similarly to the theoretical literature, this analysis examines both the types of social networks that individuals intend to use to obtain job information as well as the types of social networks that they have used to obtain jobs.

\section{Family members}

British and Indian scientists were asked to rank on a scale of zero to ten, with zero being the lowest and ten the highest, how important different sources were in providing them with new job information. British scientists ranked family members as very low in importance, with the average respondent ranking this factor as 1. Most British scientists said that their family members had little knowledge of the industry and therefore were not critical in helping them secure new job information. Table 2 shows that 5 percent of British respondents said that family and friends would be the most important source of new job information. Of those British scientists that did rank family and friends as the most important source of new job information, the vast majority said that it was their friends rather than family members that were of critical importance. 
Table 2: The most important sources of new job information

\begin{tabular}{|l|l|l|}
\cline { 2 - 3 } \multicolumn{1}{l|}{} & British scientists & Indian scientists \\
\hline Colleagues & $28 \%$ & $32 \%$ \\
\hline Business associates & $67 \%$ & $59 \%$ \\
\hline Family and friends & $5 \%$ & $9 \%$ \\
\hline
\end{tabular}

Given that British and Indian respondents were working in specialised fields of science, it is not surprising that they largely cited family and friends as an unproductive job source because they are less likely to have family members and friends in the same line of work. This research finds that British and Indian scientists holding senior management and junior positions show no significant difference in their reliance on family contacts for job information. Scholars argue that migrants who hold more senior positions are less likely to use kinship and friendship networks than migrants that occupy more junior positions (Wegener 1991). Wong and Salaff (1998) argue that 'middle class' and 'working class' migrants rely on strong ties for job purposes. The former rely principally on professional contacts and the latter rely principally on family connections.

No British respondent said that family members were important when they were asked in an open-ended question what types of people helped them find new jobs. Michael Lawson, Vice-President of a large R\&D management consultancy company, said that his family were not in his area of business and he principally relied on his business circuit of friends. This supports Campbell's (2001) research which finds that family and friends are not popular sources of job information for skilled workers in Botswana. This is in contrast to Granovetter's (1995: 41-42) research on PTM workers in Newton where he found that 31.4 percent of respondents relied on family members or friends when they found their job through a contact. Therefore, the analysis should move beyond the observation that people obtain jobs through strong ties because there are many different types of social networks that help highly skilled migrants in this regard depending upon the type of work. This research suggests that Wegener's (1991) and Wong and Salaff's (1998) argument that workers who hold higher positions within companies are more likely to use professional as opposed to family networks is too reductionist to apply to highly skilled migrants. 


\section{Graph 2: Ranking the importance of different sources for new job information}

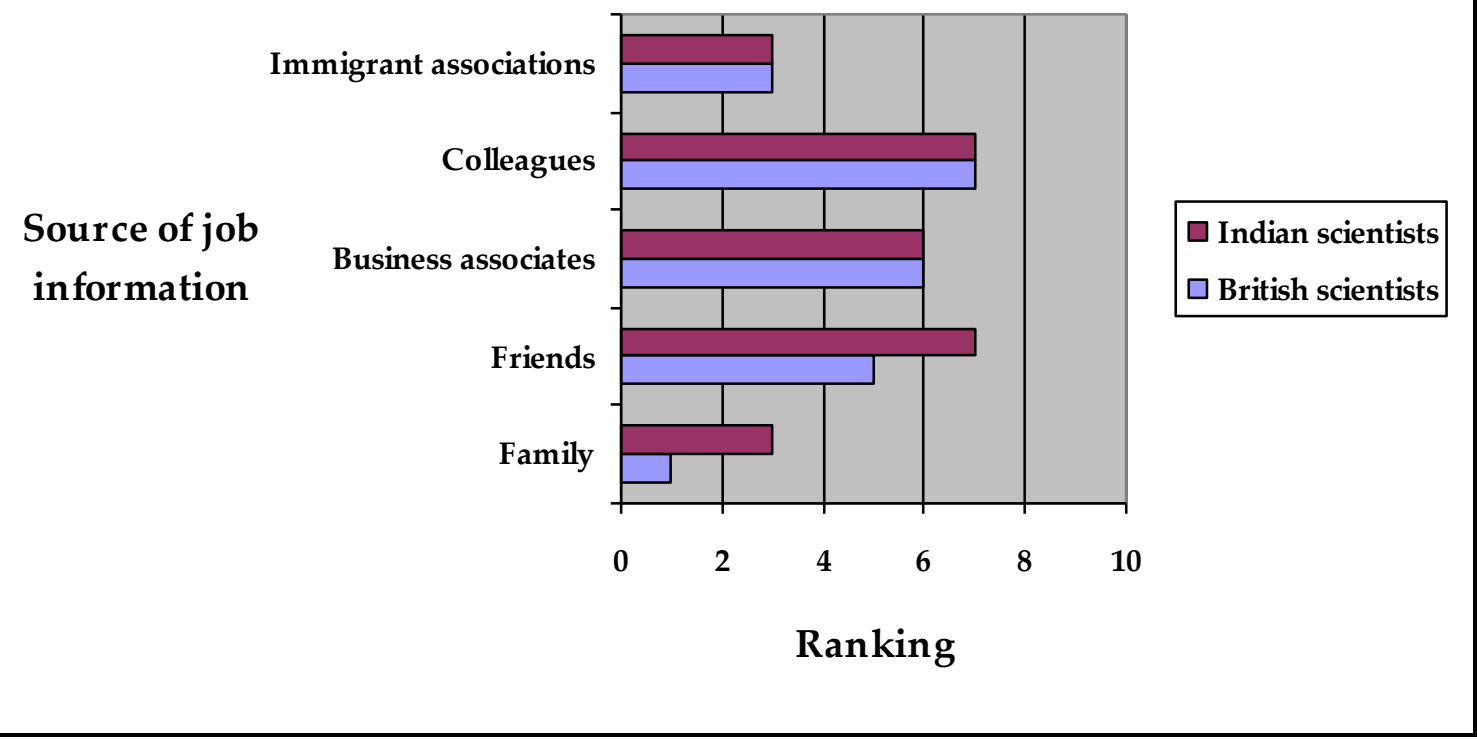

Indian scientists also did not consider family members an important source of new job information. The average Indian respondent ranked family members as 3 in importance. Thirty percent of Indian respondents ranked family members as zero in importance as a source of new job information. Raahi Saad, Director of a large pharmaceutical company, argued that family members are unlikely to be an important job source: "Unless your family is extremely well connected then the family has absolutely no clue." Having said this, there were a significant proportion of Indian scientists (24 percent) that ranked family members as at least seven in importance. Aalia Eila, scientist at a large pharmaceutical company, said that she treated information from her family particularly seriously: "Because you tend to trust them more about their experiences and they tend to be more open."

The average Indian respondent found family members more important in many facets of their professional life compared to the average British respondent (see Graph 2). This is critical because it suggests that the culture of making professional decisions is more of a family decision for Indian respondents compared to British respondents. Nabha Madhu, senior scientist of a medium biotechnology company, said that she did not communicate a great deal with colleagues at work or people from other companies, but spoke about opportunities more frequently with family members. Having said this, similarly to British respondents, those Indian respondents that cited family members as a 
low source of job information said that they were unimportant because they worked in different fields.

British and Indian respondents cited family members as a low source of new job information, although a significant proportion of Indian scientists found them important. ${ }^{6}$ These results show that most respondents did not find this strong tie important as a job source. The fact that 1 percent of British scientists and 24 percent of Indian scientists ranked family members as important shows that the debate over the significance of strong ties as a job source is nuanced. British and Indian scientists varied in how highly they regarded family members, which suggests that there are marked differences between migrant groups in terms of how frequently they used strong ties. Indian scientists were highly segmented with 30 percent of respondents ranking family members as zero and 24 percent of respondents ranking them as at least seven in importance. Therefore, it is problematic to argue that British and Indian scientists rely on weak ties because there are individual differences between and within both groups.

\section{Friends}

British scientists cited friends as moderately important in providing them with new job information. The average British respondent ranked friends as five in importance. Paul Wilson, science business consultant, argued that he would be unlikely to approach family and friends for job information: "It's pretty specialised and I couldn't really expect family and friends to have that kind of information". Ryan Church, Chief Scientific Officer at a large biotechnology company, agreed: "Family and friends I kind of discount because they have a lack of knowledge." On the other hand, David Rawson, manager at a large pharmaceutical company, said that one particular friend had proved extremely important in helping him secure a job: "One of the guys who I used to work with went for interview here and he asked about the structure of the company at interview - he did a five minute sales pitch for me - he was an important friend. Another friend was also instrumental. You can read about a company in the press, but the best way of learning about the job is from someone who works there - you don't get that information from any other source." A significant proportion of British respondents (44 percent) ranked friends as at least seven on a zero to ten scale, which, in addition to the qualitative responses, demonstrates that they were segmented in how highly they regarded friends as a job source.

\footnotetext{
${ }^{6}$ Even when family members worked in the scientific sector this did not necessarily mean they were important job sources.
} 
In most cases, British respondents said that their social networks with friends were important only if they were working in the same sector. Typically, British scientists did not know many friends working in the pharmaceutical and biotechnology sector and therefore ranked them as moderately important for providing them with new job information. A number of British respondents said that they were friendly with colleagues and scientists from other companies, but these contacts were not coded as friends because respondents initially met them in the workplace and regarded them as professional rather than friendship contacts.

More Indian than British scientists ranked friends as an important job source. The average Indian respondent ranked friends as seven in importance. In addition, 55 percent of Indian respondents ranked friends as at least seven in importance. Sana Riti, scientist at a large pharmaceutical company, said that she relied on friends because she has only been working in the pharmaceutical industry for a short period of time and therefore has only a limited number of close contacts within the workplace. Amir Syed and Nand Pran, President and CEO of two different small biotechnology companies, said that friends were of limited influence because they did not necessarily work in the same field and therefore did not have as many recommendations. Despite the above examples, junior workers showed no difference to senior management workers in how importantly they ranked friends as a job source. This again questions Wegener's (2001) and Wong and Salaff's (1998) argument that there is an occupational segmentation with senior workers using business and professional ties and junior workers using business, friendship and family ties as sources of job information.

The fact that 44 percent of British scientists and 55 percent of Indian scientists said that friends were an important source of new job information suggests that strong ties are significant. This is in contrast to family members who most respondents cited as insignificant for job information, which suggests that strong ties are less important. Mattingly (1999) and Sanders et al. (2002) argue that family members and friends are key sources of job information for helping migrants secure low-end jobs. In contrast, strong ties were less important for highly skilled British and Indian scientists. Indian respondents tended to rely more on friends as a job source than British scientists. This is owing to larger numbers of Indian scientists working in the pharmaceutical and biotechnology sector around Boston, as well as the stronger values that Indians place on friends as a job source. In short, Ooka and Wellman (2003) are right that the analysis should move beyond strong versus weak ties because the use of both 
types of contacts is highly individualised. Although there are significant trends such as friends being important strong ties for many respondents, the debate is much more complex.

\section{Colleagues and business associates}

Colleagues are understood here as people that respondents work with, whereas business associates are professionals who work in different companies who respondents come across from time to time in the course of their work such as at an annual conference. Over one-quarter of British expatriates (28 percent) and nearly one-third of Indian expatriates (32 percent) said that colleagues would be the most important source of new job information. Many British respondents said that if they were looking for a new job then they would be unlikely to approach colleagues because they would not want people in their company to know they were leaving. Tom Clayton, Chief Scientific Officer at a medium biotechnology company, said: "I wouldn't want to broadcast to people within the company that I was looking for other work." Satra Sarvang, Director of a large biotechnology company, argued that people outside of the company are likely to know more about opportunities in their company than anyone else: "Because externally most people if there are job opportunities outside then they will know better than people internally about those companies. That's where the network comes into it. Right now, to be frank ninety percent of the people will try and keep it confidential if they are moving so information internally is low." Charles Morris, Vice-President of a medium pharmaceutical company, also argued that he would be unlikely to consult colleagues for new job information: "If I am looking for a new job, unless I am made redundant, I am hardly likely to advertise the fact within my present company. I would network with friends and associates in the industry, and also contact some search agencies I know of."

In other words, although a significant proportion of British and Indian respondents argued that colleagues could provide important job information, most respondents argued that they would be less likely to approach them because they would not want people from their company knowing that they were looking for a new job. This is significant theoretically because it shows that respondents want to use their social networks to obtain new job information (Granovetter, 1974; 1995; Poros, 2001), but most are reluctant to use the social networks of their colleagues. Therefore, a significant proportion of British and Indian respondents use these strong ties for job purposes, although a greater proportion (67 percent and 59 percent respectively) use business associates or weak ties. This is important because British and Indian scientists use both types of ties for gaining job information. Again, highly skilled migrants do not rely 
wholly on strong or weak ties, but on both types of contacts.

British senior management workers were particularly unlikely to use colleagues to find out about new job information. Most British and Indian respondents holding senior management positions (75 percent and 57 percent, respectively) said that they held more social relationships with people outside of their company than inside. Therefore, they would avoid using contacts within their company. In addition, senior management positions were more difficult to fill in the pharmaceutical and biotechnology sector around Boston. As a result, senior workers would often contact other senior workers outside of their companies to advertise key vacancies. Simon Halliday, CEO and President of a medium biotechnology company, for example, said: "Either someone would call me, or if I was leaving I would go to a head-hunter. Most people when they lose a job they network with people, or get a call from someone." Ursala Richards, CEO of a medium biotechnology company, also said that she would need to be cautious about who she asked about job information: "As CEO, I would have to be very confidential if I ever wanted a new position." These findings link to the argument of homophily, which claims that people interact more with those with similar social characteristics to themselves. Therefore, because many British and Indian scientists hold senior positions within their companies and have worked in the U.S. for an extended period of time, they are likely to find a job through their extensive social networks outside of the firm.

British scientists at more junior positions held a similar number of professional contacts outside as inside of their company. They argued that they relied on both business associates and colleagues for job information. Douglas Royds, medicinal chemist at a large pharmaceutical company, argued that his colleagues were important sources of information for him because they came from a range of backgrounds. "Mainly because small companies attract people from a large background. So they all know someone who knows someone from somewhere - the whole networking and reputation thing." Surprisingly, most Indian scientists holding junior positions relied on business associates for job information (63 percent), which was 6 percent more than Indian scientists holding senior management positions. This is because the new generation of Indian scientists have undergone postgraduate and postdoctoral training in the U.S. and therefore have extensive social networks in science that are not limited to their workplace. Both of these findings contest the argument that senior workers rely more on weak ties than junior workers. In other words, there is no significant difference between senior and junior workers in terms of the types of ties they use for job information. 
The above results suggest that strong and weak ties are important for migrants working at different positions within the pharmaceutical and biotechnology sector. Table 3 shows that 18 percent more British scientists holding senior management positions, for example, rely on weak ties than Indian scientists holding senior management positions. Whereas 15 percent more Indian scientists holding junior positions rely on weak ties than British scientists holding junior positions. These results highlight that our analysis of social networks and getting jobs should move beyond the argument that certain types of workers rely on strong ties or weak ties. My data shows that the choice of whether to use strong or weak ties is highly individualised and cannot be characterised by occupational status or migrant group, for example.

Table 3: The types of ties that British and Indian scientists use for job purposes ${ }^{7}$

\section{Senior management positions}

British scientists

Strong ties $\quad 21 \%$

Weak ties $\quad 75 \%$

Indian scientists

Strong ties $\quad 34 \%$

Weak ties $\quad 57 \%$

\section{Junior positions}

British scientists

Strong ties $\quad 45 \%$

Weak ties $\quad 48 \%$

Indian scientists

Strong ties $\quad 29 \%$

Weak ties $\quad 63 \%$

\section{Expatriates}

In terms of a job source, Graph 2 shows that both groups ranked immigrant associations as low as three in importance on a zero to ten scale. ${ }^{8}$ In addition, 37 percent of British and 28 percent of Indian respondents said that immigrant associations were of zero importance as a source of new job information. Deven Paney, chief surgeon at a large hospital, for example, said that attending immigrant association meetings was not an effective way of obtaining a job: “Going to TiE [The Indus Entrepreneurs] hasn't been as fruitful

\footnotetext{
7 The percentages in this table do not add up to one hundred because some respondents did not provide complete answers.

${ }^{8}$ Immigrant associations provide social support for people from the same country of birth, particularly new arrivals.
} 
for getting jobs, but good to network. I would say 5 percent get jobs out of it." At the time of the fieldwork, the average British and Indian scientist had lived in the U.S. for twelve and fourteen years, respectively. The fact that both groups had lived in the U.S. for an extensive period of time and were well integrated into the host country explains why they did not necessarily consider other expatriates as an important job source.

The vast majority of British (91 percent) and Indian (92 percent) scientists said that they had met other British expatriates in the Boston area. However, although 40 percent of British and 59 percent of Indian respondents said that fellow British and Indian expatriates were useful for providing them with information on new job opportunities, this information rarely led to them securing a job. Many British respondents said that they had not been looking for a job since arriving in Boston and therefore had not considered using their expatriate social networks. Michael Williams, senior scientist at a small biotechnology company, stated: "I've only been job hunting once so my job exposure is limited. I've not used them so far, but they are potentially useful." The majority of British expatriate scientists (79 percent) said that they tried to separate their friends from their colleagues and because a number of their friends were British, they attempted to keep them as friends rather than try and form business alliances with them as well. In addition, a large number of British respondents said that their British friends worked in different sectors and therefore were of limited importance if they were seeking new job information.

The average Indian scientist formed close social relationships with other Indian expatriates around Boston. In large part these social relationships were for social purposes and many respondents said that they formed these social relationships when they first arrived in the region. From a job perspective, although Indian scientists said that other Indians were an important source of job information, most respondents had not gained a job through expatriate social networks. Rajeev Bhupal, scientist of a large pharmaceutical company, argued that Indian scientists were not any more significant than other contacts: "All the jobs and interviews I've got have been through other people and not Indians." In short, expatriate social networks and immigrant associations were of little importance for highly skilled British and Indian scientists looking for jobs. This is in contrast to Saxenian's (2006) and Bashi's (2007) research who find that participating in immigrant social networks can help provide migrants with new job opportunities.

Theoretically, it is problematic to argue that highly skilled migrants depend upon expatriate social networks or immigrant associations for the 
purposes of gaining new job information. In spite of a significant number of British and Indian scientists interviewed, there is a strong perception that expatriate social networks are unimportant for job purposes around Boston. This is important because a large expatriate population does not necessarily mean an active expatriate social network. Scott (2007) finds a similar trend among British expatriates in Paris. However, Saxenian (2006) and Beaverstock (2002) have shown that large expatriate populations can lead to dense expatriate social networks, which often help members find jobs.

\section{CONCLUSIONS}

The theoretical literature on getting jobs has stressed the importance of personal contacts (Granovetter 1974, 1995; Poros 2001). This paper has also emphasised the significance of such personal contacts for helping highly skilled migrants obtain employment. However, the literature also predominantly suggests that jobseekers either preference strong or weak ties. I find that British and Indian scientists tend to use both types of ties as a source of job information. In addition, senior and junior workers within both groups showed no particular preference for using strong or weak ties. Therefore, it would be wrong to suggest that highly skilled workers prefer exclusively strong or weak ties (cf. Granovetter 1973; Wegener 1991; Bian and Ang 1997; Mattingly 1999; Sanders et al. 2002). I do not doubt that "Acquaintances, as compared to close friends, are more prone to move in different circles than one's self" (Granovetter 1995: 52-53), but information from close friends and colleagues is often more candid and trustworthy. Additional research is needed to show the extent to which different social contacts are important for job purposes in other industrial sectors.

This paper shows that there is no particular pattern in whether highly skilled migrants preference strong and weak ties. British and Indian scientists argued that colleagues (strong ties) and business associates (weak ties) were both significant in helping them find jobs. Furthermore, the majority of respondents found friends (strong ties) an important source of job information, but family members (strong ties) and fellow expatriates (strong and weak ties) unimportant in this regard. Therefore, I argue that it is problematic to assume that one particular migrant group or individual relies on strong ties in lieu of weak ties, or vice-versa. Indeed, the boundary between strong and weak ties is so blurred in the context of this research that I question the significance of distinguishing the two. What is more critical is understanding who highly skilled migrants consult for new job information, rather than debating whether they are strong or weak ties. 


\section{ACKOWLEDGEMENTS}

I would like to thank the editor, Ali Rogers, as well as Mia Gray, Franz Huber, Karenjit Clare and three anonymous referees for providing extremely helpful comments on a previous draft of this paper.

\section{REFERENCES}

Alarcón, R. (1999) 'Recruitment Processes Among Foreign-Born Engineers and Scientists in Silicon Valley', American Behavioral Scientist, 42 (9), 1381-1397.

Baláž, V. and A. M. Williams. (2004) 'Been There, Done That': International Student Migration and Human Capital Transfers from the UK to Slovakia', Population, Space and Place, 10, 217-237.

Bagchi, A. D. (2001a) Making Connections. A Study of Networking among Immigrant Professionals. New York, LFB Scholarly Publishing LLC.

Bagchi, A. D. (2001b) 'Migrant networks and the immigrant professional: An analysis of the role of weak ties', Population Research and Policy Review, 20, 9-31.

Bashi, V. F. (2007) Survival of the knitted. Immigrant Social Networks in a Stratified World. Stanford, California, Stanford University Press.

Beaverstock, J. V. (2002) 'Transnational elites in global cities: 'British expatriates in Singapore's financial district', Geoforum, 33, 525-538.

Beaverstock, J. V. (2004) 'Managing across borders': knowledge management and expatriation in professional service legal firms', Journal of Economic Geography, 4 (2), 157-179.

Beaverstock, J. V. (2005) 'Transnational elites in the city: 'British highly-skilled inter-company transferees (ICTs) in New York City's Financial District', Journal of Ethnic and Migration Studies, 31, 245-268.

Bian, Y. and Ang, S. (1997) 'Guanxi Networks and Job Mobility in China and Singapore', Social forces, 75 (3), 981-1005

Burt, R. S. (2004) 'Structural Holes and Good Ideas', American Journal of Sociology, 110 (2), 349-399.

Campbell, E. K. (2001) 'Preference for Emigration among Skilled Citizens in Botswana', International Journal of Population Geography, 7, 151-171. 
Chacko, E. (2007) 'From brain drain to brain gain: reverse migration to Bangalore and Hyderabad, India's globalizing high tech cities' GeoJournal, 68, 131-140.

Chapple, K. (2002) "I Name It and I Claim It-In the Name of Jesus, This Job Is Mine': Job Search, Networks, and Careers for Low-Income Women', Economic Development Quarterly, 16(4), 294-313.

Dustmann, C. (1994). 'Speaking fluency, writing fluency and earnings of migrants', Journal of Population Economics, 7, 133-156.

Elliot, J. R. (2001) 'Referral Hiring and Ethnically Homogeneous Jobs: How Prevalent Is the Connection and for Whom?', Social Science Research, 30, 401-425.

Grabher, G. (2006) 'Trading routes, bypasses, and risky intersections: mapping the travels of 'networks' between economic sociology and economic geography', Progress in Human Geography, 30 (2), 163-189.

Granovetter, M. S. (1973) 'The strength of Weak Ties', The American Journal of Sociology, 78 (6), 1360-1380.

Granovetter, M. S. (1974) A Study of Contacts and Careers, Cambridge MA: Harvard University Press.

Granovetter, M. S. (1995) Getting a Job: A Study of Contacts and Careers $2^{\text {nd }}$ ed. Chicago: Chicago University Press.

Gray, M., Kurihara, T., Hommen, L. and Feldman, J. (2007) 'Networks of exclusion: job segmentation and social networks in the knowledge economy', Equal Opportunities International, 26 (2), 144-161.

Hanson, S. (2000) 'Networking', The Professional Geographer, 52 (4), 751-758.

Heimer, C. A. (1984) 'Organizational and Individual Control of Career Development in Engineering Project Work', Acta Sociologica, 27 (4), 283-310.

Heimer, C. A. (1992) ‘Doing Your Job and Helping Your Friends: Universalistic Norms about Obligations to Particular Others in Networks', in N. Nohria and R.G. Eccles (eds) Networks and Organizations: Structure, form, and action, Boston, Massachusetts: Harvard Business School, 143-164.

Kadushin, C. (2004) 'Too Much Investment in Social Capital?, Social Networks, 26, 75-90.

Larner, W. (2007) 'Expatriate experts and globalising governmentalities: the New Zealand diaspora strategy', Transactions of the Institute of British Geographers NS, $32,331-345$. 
Lin, N. (2001) Social Capital. A Theory of Social Structure and Action Cambridge: Cambridge University Press.

Marsden, P. V. and K. E. Campbell. (1984) 'Measuring Tie Strength', Social Forces, 63 (2), 482-501.

Massey, D. S., L. Goldring, and J. Durand. (1994) 'Continuities in Transnational Migration: An Analysis of Nineteen Mexican Communities', The American Journal of Sociology, 99 (6), 1492-1533.

Mattingly, D. (1999) 'Job search, social networks, and local labor market dynamics: the case of paid household work in San Diego, California', Urban Geography, 20, 46-74.

McDowell, L. (2005) 'Love, money and gender divisions of labour: some critical reflections on welfare-to-work policies in the UK', Journal of Economic Geography, 5 (3), 365-379.

McDowell, L. (2007) 'Respect, respectability, deference and place: What is the problem with/for working class boys?', Geoforum, 38 (2), 276-286.

Montgomery, A.F. (2008) 'Virtual enclaves: the influence of alumni email lists on the workspaces of transnational software engineers', Global Networks, 8 (1), 71-93.

Ooka, E. and Wellman, B. (2003) 'Does Social Capital Pay Off More Within or Between Ethnic Groups? Analyzing Job Searches in Five Toronto Ethnic Groups', in Fong, E.(ed) Inside the Mosaic Toronto: Toronto University Press, 119226.

Poros, M. V. (2001) 'The role of migrant networks in linking local labour markets: the case of Asian Indian migration to New York and London', Global Networks, $1(3), 243-260$.

Portes, A. (1998) 'Social Capital: Its Origins and Applications in Modern Sociology', Annual Review of Sociology, 24, 1-24.

Pratt, G. and S. Hanson. (1994) 'Geography and the Construction of Difference.', Gender, Place, and Culture, 1, 5-29.

Raunio, M. and M. Sotarauta. (2005) 'Highly Skilled Labor Force in the Global Field of Choices: Case Finland.' Presented at Oxford Round Table, July 31st August 5th, 2005, St Antony's College, University of Oxford.

Sanders, J., V. Nee, and S. Sernau. (2002) 'Asian Immigrants' Reliance on Social Ties in a Multiethnic Labor Market', Social Forces, 81 (1), 281-314. 
Saxenian, A. (2002) 'Silicon valley's new immigrant high-growth entrepreneurs', Economic Development Quarterly, 16 (1), 20-31.

Saxenian, A. (2006) The New Argonauts. Regional Advantage in a Global Economy Cambridge, Massachusetts: Harvard University Press.

Scott, S. (2007) 'The Community morphology of skilled migration: the changing role of voluntary and community organisations (VCOs) in the grounding of British identities in Paris (France)', Geoforum, 38 (4), 655-676.

Scott, S. (2006) 'The social morphology of skilled migration: The case of the British middle class in Paris', Journal of Ethnic and Migration Studies, 32 (7), 11051129.

Squires, G. D. and Kubrin, C. E. (2005) Privileged Places: Race, Uneven Development, and the Geography of Opportunity in Urban America', Urban Studies, 42, 47-68.

U.S. Census Bureau. (2000) Census 2000 Summary File 3 Matrices PCT15 and PCT18.

Wadhwa, V., Saxenian, A., Rissing, B. and G. Gereffi (2007) 'America's New Immigrant Entrepreneurs', Duke School of Engineering and UC Berkeley School of Information.

Walsh, K. (2006) 'Dad says I'm tied to a shooting star!' Grounding (research on) British expatriate belonging', Area, 38 (3), 268-278.

Wegener, B. (1991) 'Job Mobility and Social Ties: Social Resources, Prior Job, and Status Attainment', American Sociological Review, 56 (1), 60-71.

Williams, A. M. (2006) 'Lost in translation? International migration, learning and knowledge', Progress in Human Geography, 30, 588-607.

Williams, A. M. (2007) 'International labour migration and tacit knowledge transactions: a multi-level perspective', Global Networks 7 (1), 29-50.

Williams, A.M. and V. Baláž. (2005) 'What human capital, which migrants? Returned skilled migration to Slovakia from the U.K.', International Migration Review, 39 (2), 439-468.

Wong, S. and J. W. Salaff. (1998) 'Network Capital: Emigration from Hong Kong', The British Journal of Sociology, 49(3), 358-374. 